\title{
Series on vascular injuries: complex injuries and difficult problems. Surgical strategies for their management
}

\author{
Editors: \\ Dr. Juan A. Asensio, University of Miami, Miami, Florida \\ Dr. David V. Feliciano, Emory University, Atlanta, Georgia \\ Dr. Donald D. Trunkey, University of Oregon, Portland, Oregon \\ Dr. Ari Leppaniemi, Helsinki University, Helsinki, Finland
}

\author{
J. A. Asensio \\ Published online: 11 October 2011 \\ (C) Springer-Verlag 2011
}

It is an honor to edit these three volumes of the European Journal of Trauma and Emergency Surgery dedicated to the management of vascular injuries. This request originated from Dr. Ingo Marzi, a prestigious colleague, dedicated surgeon, and chief editor, as well as from the rest of the members of the editorial board. It is also an honor to have as my co-editors three nationally and internationally renowned surgeons that have made major contributions to the field of Trauma and, specifically, Vascular Trauma. Dr. David V. Feliciano is considered to be amongst the most renowned experts in this field, Dr. Donald D. Trunkey is the Dean of the world's trauma surgeons, and Dr. Ari Leppaniemi has also made major contributions to this field.

Vascular injuries are amongst the most difficult injuries and complex problems encountered by trauma surgeons. The field of vascular injury management was born during the many different wars and conflicts that our world has experienced. Ambrose Paré, one of the earliest pioneer trauma surgeons, abandoned the use of boiling oil to cauterize wounds and introduced the ligature to control bleeding vessels; along with Scultetus, he developed the very first vascular clamp, known as "Le Bec de Corbin". Many contributions and contributors have emerged from battlefields that are too numerous to cite. Be that, as it may, for many of us academic surgeons that have operated in wartime as well as in low-intensity unnamed conflicts, we know and carry the name of these pioneers close to our hearts.

\footnotetext{
J. A. Asensio ( $\square)$

Division of Trauma Surgery and Surgical Critical Care, DeWitt Daughtry Family Department of Surgery, Ryder Trauma Center, University of Miami Miller School of Medicine, 1800 NW 10th Avenue, Suite T-247, Miami, FL 33136-1018, USA

e-mail: jasensio@med.miami.edu
}

Our world remains a dangerous place; man's inhumanity for man knows no boundaries. The world's trauma surgeons continue to remain an elite "Band of Brothers", this brotherhood is well described by Shakespeare's King Henry V: "That he which hath no stomach to this fight, let him depart; his passport should be made and crowns for convoys put in his purse, we will not die in that man's company that fears his fellowship to die with us. From this day to the ending of the world, but we in it should be remembered; we few, we happy few, we BAND OF BROTHERS; for he that today sheds his blood with me shall be my brother..." (Henry V, Act 4, Scene 3).

There is no better document than the American Declaration of Independence to signal man's equality and the sanctity of human rights: "We hold these truths to be selfevident, that all men are created equal; that they are endowed by their Creator with certain unalienable rights that among these are life, liberty and the pursuit of happiness..."

It is my strong belief that every injured patient, every wounded soldier, every innocent bystander, every man, woman, or child caught in the crossfires of endless and useless wars has an unalienable right to have their life saved, their pain mitigated, and their limbs spared. These are also basic human rights. Nobody better than trauma surgeons that have been in battlefields and have witnessed the horrors of war, both in military and urban areas of trauma, are more familiar with this concept. How true do the words of Hippocrates still sound today: "Let him, who wishes to be a surgeon, go to war".

We must give credit to the great pioneers in this field that came before us. Surgeons like Vojislav Soubbotich, who first began to report vascular injuries and their early management during the Serbo-Turkish and Serbo-Bulgarian wars. Sir George Makin, whose textbook based on the British experience during World War I (WWI) remains, to 
this day, the model illustrating the didactic approach to these injuries. Michael De Bakey and Fiorindo Simeone's classical study of World War II (WWII) paved the way for the advancements that were later to be made during the Korean conflict. Carl Hughes and Edward Jahnke, along with Frank Spencer and John Malone Howard, began an intensive approach to repair these injuries during the Korean conflict. And, of course, Vietnam, the conflict that set the trend for the management of vascular injuries. Norman Rich, with the creation of the Vietnam Vascular Registry and his Vascular Trauma Textbook, remains the classical treatise on vascular injury management. Contributions by Drs. Rich, George Lavenson, and many others defined the field for Vascular Trauma Management. The knowledge derived from the Vietnam Vascular Registry has allowed many wounded soldiers in many wars and conflicts, and particularly during our recent conflicts in Iraq and Afghanistan, to have their lives spared and their limbs saved. To them, we owe a tremendous debt of gratitude. Sadly enough, few know that, today, only $37 \%$ of the Vietnam veterans remain alive (personal communication, Dr. Norman Rich, Chicago, Illinois, June 2011), and many remain homeless.

These three issues are dedicated to Dr. Norman Rich, a friend, distinguished colleague, and mentor, a true professor. We are all indebted to him. These issues are also dedicated to all wounded soldiers, past, present, and, unfortunately, future, that will experience the pain of the battlefield. It is sad that humanity still has not been able to find a formula to peacefully resolve our problems. Because humanity's failure at peaceful co-existence, I know that trauma surgeons will remain forever engaged in the sacred effort of trying to save lives. Our main goal is to prevent mothers, fathers, sisters, and brothers from having to stand above the caskets of young men that have been killed in combat.

Once again, I challenge, I urge, I beseech all my colleagues in Trauma Surgery to go beyond the walls of academia, to serve those who must be served, to use the power of our profession to exercise our consciences, to serve as leaders and advocate for human rights, to heal the wounded, and to teach and forge the future generations of those that will be given the great gift to perform Trauma Surgery. We must be prepared to take forth the challenge, to create peace, and to heal wounds because it is us and those that have come before us which have held the hands of the wounded and the injured, filled with our own pain and crying, often inwardly, when a life is lost while continuing the never-ending struggle to save lives. Our principles should always remain steadfast. They are: to save lives, cure disease, and alleviate pain.

It is my most fervent hope, along with that of my coeditors and contributors to these issues, that the knowledge contained in these issues will be wisely used to save lives and teach others how to save lives. This is our most sacred commitment. Once again, I would like to thank Dr. Marzi and all of my colleagues on the editorial board for the faith placed on us. I would also like to recognize Dr. Federico Mazzini of the Hospital Italiano de Buenos Aires, our current Chief Research Fellow and International Visiting Scholar, for his superb efforts in coordinating the academic initiatives leading to the compilation of these issues. May we all continue to advance the field of Trauma Surgery and Vascular Injury Management. No greater commitment exists among trauma surgeons than to save lives and advocate for peace.

Conflict of interest None. 